\title{
Review
}

\section{Routine Childhood Vaccination During COVID-19 in Saudi Arabia: A Systematic Review}

\author{
Razan Alghanmi ${ }^{1}$, Suhaib Refae ${ }^{2}$, Sarah Asiri ${ }^{3}$, Hanan Bamarouf ${ }^{4}$, Jwael Alhamoud ${ }^{5}$, Mohammad Alamri ${ }^{6}$, Khalid Alsaedi ${ }^{7}$, \\ Reem Alfares ${ }^{8}$, Maram Al-qarni ${ }^{9}$, Ghadeer Alwazzan ${ }^{8}$, Ghaya Fatani ${ }^{5}$ \\ ${ }^{1}$ Department of Pediatrics, East Jeddah Hospital, Jeddah, Saudi Arabia \\ ${ }^{2}$ Department of Pediatrics, Al Thager General Hospital, Jeddah, Saudi Arabia \\ ${ }^{3}$ College of Medicine, Ibn Sina National College, Jeddah, Saudi Arabia \\ ${ }^{4}$ College of Medicine, Batterjee Medical College, Jeddah, Saudi Arabia \\ ${ }^{5}$ College of Pharmacy, Batterjee Medical College, Jeddah, Saudi Arabia \\ ${ }^{6}$ College of Medicine, King Saud bin Abdulaziz University for Health Sciences, Riyadh, Saudi Arabia \\ ${ }^{7}$ Department of Pharamacy, King Abdullah Medical City, Mecca, Saudi Arabia \\ ${ }^{8}$ General Practiitoner, Ministry of Health, Qatif, Saudi Arabia \\ ${ }^{9}$ Department of Pharamacy, King Faisal Hospital, Taif, Saudi Arabia
}

Correspondence should be addressed to Dr. Razan Abdulaziz Alghanmi Department of Pediatrics East Jeddah General Hospital Jeddah, Saudi Arabia Email: ralghanmi@moh.gov.sa

Received 6 June 2021; Revised 9 June 2021; Accepted 14 June 2021; Published 16 June 2021

Copyright (C) 2021 Alghanmi et al. This is an open access article distributed under the Creative Commons Attribution License, which permits unrestricted use, distribution, and reproduction in any medium, provided the original work is properly cited.

\begin{abstract}
Although adhering to the timelines of childhood vaccinations is essential to achieving favorable outcomes, many previous investigations have reported a potential delay in vaccination schedules due to many reasons, including natural disasters, which may have a significant impact on public health, subsequently causing remarkable outbreaks of vaccinationpreventable diseases. The study aim is to assess the impact of the COVID-19 pandemic on routine pediatric vaccination and the associated factors in Saudi Arabia. A systematic review was conducted to identify relevant articles that investigated the impact of the COVID-19 pandemic on pediatric vaccination and the associated factors in Saudi Arabia. A total of three relevant cross-sectional studies were included and was conducted in three different regions: Qassim, Riyadh, and Eastern region. The three studies reported three variable rates for routine vaccination delays of $23.4 \%$, $72.9 \%$, and $33.1 \%$. As for prevalence per childhood vaccination schedules, two studies reported that the highest prevalence rates were reported in two and four month vaccinations, while the third study reported that the highest rates were noticed at 12 and 18 months. Fear of COVID-19 infection was the most common cause of delayed or missed vaccination. Family size, having medical insurance, caregiver age ranges between 18-30 and being a healthcare worker were the most common factors that significantly influenced caregivers to vaccinate their children on time. Further efforts and innovative approaches by healthcare officials are needed to enhance vaccination rates during times of emergency and to implement home visit programs in association with the primary healthcare section.
\end{abstract}

Keywords: COVID-19; pediatrics; vaccination; immunization; epidemiology, delay, Saudi Arabia. 
Journal of Healthcare Sciences

\section{Introduction}

The COVID-19 pandemic is a recent worldwide crisis caused by the severe acute respiratory syndrome coronavirus 2 (SARS-CoV-2), first reported in late 2019 in Wuhan, China. Many public health issues have been aroused as a result of the heavy burden that the pandemic has placed upon almost all global healthcare systems(1). Accordingly, efforts were made to introduce innovative interventional approaches that may limit the transmission of the disease, including travel restrictions, national lockdowns, and broad screening for the infections $(2,3)$.

Moreover, school lockdowns were also among the strategies that were utilized to limit the transmission of the disease $(4,5)$. Although it has been proven that such measures are essential in controlling the pandemic and reducing the rates of infection, studies have shown that such measures may affect the physical and mental health of children $(2,6)$. In the same context, the health of these children may also be negatively affected as studies have shown that vaccination strategies for children may have been delayed or missed (7-9). These effects could lead to significant public health concerns, including impacted herd immunity for certain vaccine-preventable diseases $(10,11)$. The latter was reported to constitute a significant threat to approximately 80 million children globally, as a result of the significant impact of COVID19 on immunization against these diseases (12).

The importance of maintaining adequate childhood vaccination also extends to reducing the severity of the disease in patients that suffer from co-morbid respiratory-related infections such as influenza and COVID-19 (13, 14). The rates of disrupted vaccination programs amid the COVID-19 pandemic have been reported to vary globally. For instance, estimates indicate that only $25 \%$ of children within the United States received their immunization shots in a timely manner $(14,15)$. In Saudi Arabia, estimates across the country indicate that the rates of missed vaccinations during childhood are hugely variable, ranging between $9 \%$ and $24 \%$. Many reasons have been reported to justify this, including a shortage of the required immunization shots at the local healthcare facilities and not attending the vaccination appointments $(16,17)$.
Although sticking to the timelines of childhood vaccinations is essential to achieve favorable outcomes, many previous investigations have reported delays in vaccination schedules due to many reasons, including natural disasters, can have a significant impact on public health, causing remarkable outbreaks of the vaccinationpreventable diseases $(7,18)$. Accordingly, many global and local recommendations were suggested to ensure a timely vaccinated children during the COVID-19 pandemic. Many global investigations have been published to assess the impact of COVID-19 on vaccination schedules (19-21), however, not many studies have been conducted within Saudi Arabia. Therefore, we aim to conduct a systematic review to assess the impact of the COVID-19 pandemic on pediatric vaccination and the associated factors in Saudi Arabia.

\section{Methods}

\section{Search strategy}

The bulk of the search strategy is comprised of online searching of databases including Scopus, PubMed, Google Scholar, Cochrane Library, The World Health Organization Virtual Health Library, Embase, and Web of Science, to find all the potential articles that could help us achieve our outcomes. The main search term that was used was ("COVID-19" OR "Coronavirus disease 2019" OR "SARS-CoV-2" OR "Coronavirus" OR "2019-nCoV") AND ("vaccine" OR "vaccines" OR "vaccination" OR "immunization" OR "immunizations")

AND ("pediatric" OR "pediatrics" OR "childhood" OR "children") AND ("Saudi" OR "Saudi Arabia"), which was also modified based on the search strategy per each database. Our search included articles that were published after the COVID-19 pandemic was first reported in late 2019 in China. Moreover, after completing the search strategy, we conducted a manual search in the references of the included citations for their potential citations from relevant journals to identify any potentially missed articles that could help us discuss the current outcomes of this study. 
Journal of Healthcare Sciences

The Preferred Reporting Items for Systematic Reviews and Meta-Analyses (PRISMA) guidelines were followed to design and conduct the current study (22).

\section{Outcomes and inclusion criteria}

The present study aims to identify the impact of the COVID-19 pandemic on routine childhood vaccination in Saudi Arabia. Accordingly, the main outcomes include the prevalence of delayed vaccination procedures and the associated factors for such delays.

Therefore, we decided to include original articles that were published during the COVID-19 pandemic in Saudi Arabia that investigated the impact of COVID-19 on routine childhood vaccinations. Articles that were not original (as thesis, reviews, perspectives, commentary, editorials, protocols, abstracts, etc.) were excluded from the current review. We also excluded articles that were not published during COVID-19 and others that were not conducted in Saudi Arabia.

\section{Screening and retrieval of the relevant articles}

Following the search strategy, the results from all databases were imported to one single Endnote sheet, which was used to eradicate the duplicated citations. The remaining articles were then grouped and exported to one excel sheet that was standardized to facilitate title/abstract screening by exhibiting all the articles with their identifications (IDs), DOIs, journal names, URLs, authors, and abstracts.

After excluding the irrelevant articles, full texts of the remaining IDs were then downloaded for another round of screening to finally include all the relevant articles that suited our intended outcomes. All of these steps were undertaken by at least four reviewers with blinding of the results from each other to prevent any potential bias in the results and under the supervision of the study senior author who made sure that all steps were undertaken in agreement with all authors and following the PRISMA guidelines.

\section{Data extraction and quality assessment}

A unified excel sheet to obtain all the relevant information from the included studies was constructed by the two authors. The sheet was formed of three tabs that included 1) outcomes: including the prevalence of delayed immunization during childhood and the associated factors that may influence the prevalence rate, and 3) quality assessment tab: which included the domains of the modified Newcastle-Ottawa Scale (NOS) for cross-sectional studies (23). The domains of the tool were established primarily to assess the compatibility and assessment of the studies, the methodology, and reporting of the outcomes. It was designed to score articles from 0 to 10 based on their quality and degree of bias. All articles were finally rated as good, excellent, satisfactory, or non-satisfactory based on their degree of bias and the estimated scores according to the NOS tool. All of the extraction steps were conducted by four reviewers and conflicts were resolved using a public discussion under the supervision of the main study author.

\section{Results}

\section{Search results}

We found a total of 242 articles from the databases as well as the manual searching which was conducted in this study. The flow of search and screening until final inclusion is presented in Figure 1. Briefly, among the included 242 studies, 169 were screened for title and abstract relevance, of which only 18 were eligible for full-text screening and only three articles were eligible for inclusion in this study, based on our aforementioned criteria.

\section{Risk of bias}

The quality assessment results for the included studies are presented in Table 1, which shows the detailed domains and scoring for each study according to the NOS tool. In summary, all studies showed good quality with minimal risk of bias as all of the included studies had a total quality score of 8 . 


\section{Journal of Healthcare Sciences}

Figure 1: The flow diagram simplifying the process of data collection and identification of the included studies

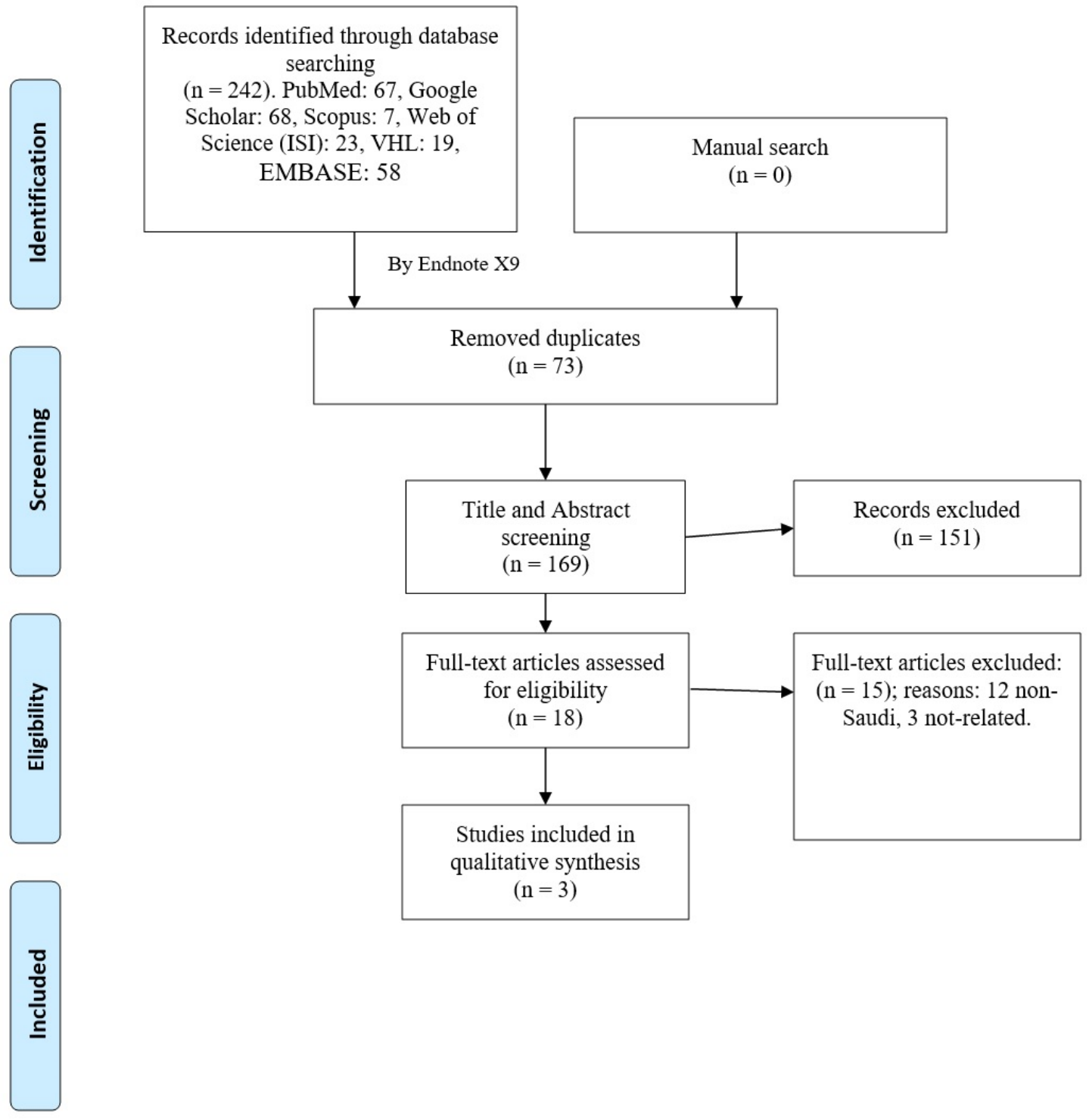

Table 1. The results of the assessed quality for the included studies using the modified Newcastle-Ottawa scale (NOS) for cross-sectional studies.

\begin{tabular}{|c|c|c|c|c|c|c|c|c|c|c|}
\hline \multirow[b]{2}{*}{ Author } & \multirow[b]{2}{*}{ Year } & \multicolumn{4}{|c|}{ Selection } & \multirow{2}{*}{$\begin{array}{c}\text { Comparability } \\
\text { The Subjects in } \\
\text { Different } \\
\text { Outcome } \\
\text { Groups are } \\
\text { Comparable }\end{array}$} & \multicolumn{2}{|c|}{ Outcome } & \multirow[b]{2}{*}{$\begin{array}{l}\text { Total } \\
\text { score }\end{array}$} & \\
\hline & & $\begin{array}{c}\text { ntativen } \\
\text { ess of } \\
\text { the } \\
\text { Sample }\end{array}$ & $\begin{array}{l}\text { Sample } \\
\text { size }\end{array}$ & $\begin{array}{c}\text { Non } \\
\text { Respondents }\end{array}$ & $\begin{array}{c}\text { Ascertai } \\
\text { nment of } \\
\text { the } \\
\text { Exposure }\end{array}$ & & $\begin{array}{l}\text { Assessment } \\
\text { of outcome }\end{array}$ & $\begin{array}{l}\text { Statistica } \\
\text { l analysis }\end{array}$ & & \\
\hline $\begin{array}{l}\text { Alsuhaiba } \\
\text { niet al. (24) } \\
\text { Alrabiaah }\end{array}$ & 2020 & + & + & + & ++ & + & + & + & 8 & Good \\
\hline $\begin{array}{l}\text { et al. }(25) \\
\text { Zainab et }\end{array}$ & 2020 & + & + & + & ++ & + & + & + & 8 & Good \\
\hline al. (26) & 2020 & + & + & + & + & ++ & + & + & 8 & Good \\
\hline
\end{tabular}


Journal of Healthcare Sciences

\section{Baseline characteristics}

We have included three studies that were conducted in Saudi Arabia in three different regions, including Qassim, Riyadh, and the Eastern regions. The two studies by Alsuhaibaniet al. (24) and Almoosa et al. were survey-based cross-sectional studies that depended on the reporting of the healthcare givers in their findings and included a total of 749 and 378 caregivers in their studies. The other investigation by Alrabiaah et al. (25) reported that their sample size encompassed children only, with a recruited sample size of 15,870 children. Other baseline characteristics and a summary of the findings of each study are presented in Table 2.

Table 2. Baseline characteristics of the included investigations in Saudi Arabia.

\begin{tabular}{|c|c|c|c|c|c|c|c|c|c|}
\hline Reference & Year & Country & Region & $\begin{array}{l}\text { Study } \\
\text { design }\end{array}$ & $\begin{array}{l}\text { Sample } \\
\text { size }\end{array}$ & Children & $\begin{array}{l}\text { Mothers } \\
\text { (n) }\end{array}$ & $\begin{array}{l}\text { Prevalence of } \\
\text { delayed } \\
\text { immunization }\end{array}$ & Investigated vaccines \\
\hline $\begin{array}{l}\text { Alsuhaibani } \\
\text { et al. (24) }\end{array}$ & 2020 & $\begin{array}{l}\text { Saudi } \\
\text { Arabia }\end{array}$ & Qassim & $\begin{array}{l}\text { Cross- } \\
\text { sectional }\end{array}$ & 749 & - & 619 & $23.40 \%$ & $\begin{array}{l}\text { hepatitis B, polio, diphtheria- } \\
\text { tetanus-pertussis, Hemophilus } \\
\text { influenzae type B, } \\
\text { pneumococcal infections, } \\
\text { rotavirus, bacillus Calmette- } \\
\text { Guérin (BCG), measles, } \\
\text { hepatitis A, varicella, } \\
\text { meningococcal infections, } \\
\text { human papillomavirus, } \\
\text { measles-mumps-rubella. }\end{array}$ \\
\hline $\begin{array}{l}\text { Alrabiaah et } \\
\text { al. (25) }\end{array}$ & 2020 & $\begin{array}{l}\text { Saudi } \\
\text { Arabia }\end{array}$ & Riyadh & $\begin{array}{c}\text { Cross- } \\
\text { sectional }\end{array}$ & $15870^{*}$ & 15870 & - & $72.90 \%$ & $\begin{array}{l}\text { Tuberculosis, poliomyelitis, } \\
\text { hepatitis B, rotavirus, } \\
\text { diphtheria, pertussis, tetanus, } \\
\text { varicella, Haemophilus } \\
\text { influenzae type b, Neisseria } \\
\text { meningitides, Streptococcus } \\
\text { pneumoniae, and measles, } \\
\text { mumps, rubella }\end{array}$ \\
\hline $\begin{array}{l}\text { Zainab et al. } \\
\text { (26) }\end{array}$ & 2020 & $\begin{array}{l}\text { Saudi } \\
\text { Arabia }\end{array}$ & $\begin{array}{c}\text { Eastern } \\
\text { region }\end{array}$ & $\begin{array}{c}\text { Cross- } \\
\text { sectional }\end{array}$ & 378 & 378 & 283 & $33.10 \%$ & - \\
\hline
\end{tabular}

*The study did not include parents and the sample size consisted of children only.

Table 3. Prevalence of pediatric immunization delays based on the perceived shots.

\begin{tabular}{|c|c|c|c|c|c|c|c|c|c|}
\hline \multirow{2}{*}{ Reference } & \multicolumn{9}{|c|}{ Prevalence of delayed immunization by month } \\
\hline & Teal & 2-month & 4-month & 6-month & 9-month & 12-month & 18-month & 24-month & Others* \\
\hline Alsuhaibani et al. (24) & 2020 & $10.20 \%$ & $7.10 \%$ & $17 \%$ & $11.30 \%$ & $17.70 \%$ & $18.60 \%$ & $12.60 \%$ & $5.50 \%$ \\
\hline Alrabiaahet al. (25) & 2020 & $80.50 \%$ & $74.40 \%$ & $72.90 \%$ & $80 \%$ & $74.10 \%$ & - & - & $16.50 \%$ \\
\hline Zainab et al. (26) & 2020 & $41.10 \%$ & $35.10 \%$ & $14.40 \%$ & $25.60 \%$ & $7.00 \%$ & $25.30 \%$ & $8.80 \%$ & $4.60 \%$ \\
\hline
\end{tabular}

\footnotetext{
*Refers to parents reporting unknown results in the first study and refers to vaccination at birth in the following two studies.
} 
Journal of Healthcare Sciences

\section{Discussion}

\section{Prevalence of delayed pediatric immunization}

Among the three included studies, all reported the prevalence of delayed routine immunization during childhood in their findings. The study by Alsuhaibani $e t$ al. (24) reported that the prevalence of delayed routine pediatric immunization in their population was $23.4 \%$ for more than one month, according to the surveyed parents. Moreover, the authors also reported the prevalence of delayed immunization shots per age. The authors reported that the highest prevalence rates of delayed pediatric immunization shots were at six months (shots: Diphtheria, Pertuss is, and Tetanus (DTaP), Inactivated Poliovirus Vaccine (IPV), Human Papilloma virus (HPV), Haemophilus Influenzae Type b (Hib), Pneumococcal Vaccine (PCV), Bacillus CalmetteGuérin Vaccine (BCG), and Rota), 12 months (shots Measles, Mumps and Rubella (MMR), Oral Poliovirus Vaccines (OPV), Meningococcal Conjugate Vaccine (MCV4), and PCV), and 18 months (shots: OPV, Hib, DTaP, MMR, Hepatitis A Vaccine (HAV), and Measles, Mumps, Rubella, Varicella Vaccine (MMR-Var) recording $17 \%, 17.7 \%$, and $18.6 \%$ prevalence rates, respectively (Table 3).

Another cross-sectional investigation was conducted by Alrabiaah et al. (25) that included a total of 15,870 children to determine the impact of the COVID-19 pandemic on childhood vaccination. The authors reported that the total reduction at 2, 4, 6, 9, and 12 months for vaccination shots was $72.9 \%$ as compared to the prevalence of vaccination delays for the same months prior to COVID-19. The authors also reported that the rates of vaccines given dropped in March, April, and May 2020 were $49.39 \%, 71.9 \%$, and $68.48 \%$ as compared to the same months from 2017-2019 (before COVID-19). It is worth mentioning that the timely prevalence of reduction rates showed that all shots from birth to 12 months were significantly reduced as compared to the era before COVID-19, and the reduction at birth was lower than at 2, 4, 6, 9, and 12 months (Table 3).
In the Eastern region of Saudi Arabia, Zainab et al. (26) reported that the prevalence of delayed immunization in their investigation was estimated to be $33.1 \%$, and the prevalence was highest at two and four months of immunization (41.1\% and $35.1 \%$, respectively). Global reports have also demonstrated the huge prevalence of delayed childhood immunization during the COVID-19 pandemic.

This was indicated in the United States as reports estimated a huge decline in routine childhood vaccinations, especially in children that are older than one month (27).

In Pakistan, a huge rate of reduction in routine childhood vaccinations was recorded, at 52\% (28). In England, previous studies also demonstrated a prevalence rate of $20 \%$ of reduced childhood MMR vaccinations administration, in addition to a significant reduction in the hexavalent vaccine, but with a rate that is less than the MMR (29).

\section{Causes of reported immunization delays}

Many reasons have been reported for pediatric immunization delays. The study by Alsuhaibani et al. (24) showed that fear of catching COVID-19 was the most common cause for delaying the immunizations $(60.9 \%)$.This is followed by time constraints $(11.6 \%)$, no scheduled vaccination appointments $(9.2 \%)$, and closed clinics, vaccines unavailability, or traveling during the scheduled time $(6.7 \%)$.

Zainab et al. (26) also stated the reasons reported by the surveyed caregivers for not attending in time to vaccinate their children during COVID-19. Similarly, having fear of catching COVID-19 in a healthcare setting was the most common reason, followed by thinking that vaccinations were not necessary for their children, no vaccinations were scheduled for their children, lockdown, thinking that vaccines were not efficacious, and previous administration of the vaccines at home, with reported prevalence rates for these reasons at $42.4 \%, 28 \%, 29.6 \%, 4 \%, 0.8 \%$ and $4 \%$, respectively. 
Journal of Healthcare Sciences

In a separate context, the authors also reported the most common causes for children being vaccinated in time. Fear of being unvaccinated, enhancing immunity, adherence to medical advice, recommendations, and advice from family and friends were the most commonly reported causes by caregivers, with estimated prevalence rates of $60.3 \%, 67.5 \%, 31.2 \%$, and $7.1 \%$, respectively. These findings are consistent with the results of previous findings in the United States (27). To overcome the fear of catching COVID-19, which is reported to be the most common cause across the studies, innovative safe approaches have been proposed. For instance, launching vaccination campaigns at home rather than in healthcare facilities, and making flexible appointments at the healthcare facilities to prevent any contact between COVID-19 patients and visitors for vaccinations has been previously proposed $(27,30)$.

\section{Associated factors with immunization delays}

The baseline demographics may play a significant role in the prevalence rate of delayed pediatric vaccination. Alsuhaibani et al. (24) demonstrated that vaccination of children to parents with medical insurance was more significant in terms of timeliness than vaccination of children to parents without medical insurances, which were delayed $(\mathrm{p}=0.043)$. Moreover, having multiple children was also a significant predictor for reporting delayed immunization as opposed to having a single child as having more than one child contributed to around three times the risk of delayed immunization ( $\mathrm{p}<$ 0.001 ). This was consistent with the findings of previous investigations outside Saudi Arabia (17, 31). This may be attributable to the potential overload on parents due to the increased tasks required for multiple children, pushing them to miss their vaccination schedules. Zainab et al. (26) reported that the young age of the caregivers (18-30 years old), being a healthcare worker, and always ensuring their children were vaccinated in time before COVID-19 were the most significant factors that were associated with lower rates of delayed immunization schedules, according to the caregivers that responded to their survey ( $p=0.004,0.001$, and 0.02 , respectively).

Our study is limited by the small number of the included studies and the limited sample size among them, which suggests that further investigations should be conducted for a better representation of the prevalence rates across Saudi Arabia.

\section{Conclusion}

This systematic review shows that the prevalence of delayed immunization in Saudi Arabia is high, and additional preventive measures are needed to improve the quality of care for affected children. Fear of catching COVID-19 and the absence of access to immunization shots are the most commonly reported reasons for such delays. Accordingly, further efforts by healthcare officials is needed for easy, timely delivery of vaccines and application of home visit programs will greatly benefit and eliminate such delays.

\section{Acknowledgement:}

The authors would like to thank the ministry of health and East Jeddah Hospital in Saudi Arabia for providing the necessary access and guideline in making of this review.

\section{Disclosure:}

\section{Statement:}

The authors declare that there is no conflict of interest.

\section{Funding:}

None

\section{Ethical consideration:}

None applicable

\section{References}

1. Hartley DM, Perencevich EN. Public Health Interventions for COVID-19: Emerging Evidence and Implications for an Evolving Public Health Crisis. Jama. 2020;323(19):1908-9.

2. Wong CA, Ming D, Maslow G, Gifford EJ. Mitigating the Impacts of the COVID-19 Pandemic Response on At-Risk Children. Pediatrics. 2020;146(1).

3. Foster P, Cheung T, Craft P, Baran K, Kryskow M, Knowles R, et al. Novel Approach to Reduce Transmission of COVID-19 During Tracheostomy. Journal of the American College of Surgeons. 2020;230(6):1102-4. 
4. Kawano S, Kakehashi M. Substantial Impact of School Closure on the Transmission Dynamics during the Pandemic Flu H1N1-2009 in Oita, Japan. PloS one. 2015;10(12):e0144839.

5. Luca G, Kerckhove KV, Coletti P, Poletto C, Bossuyt $\mathrm{N}$, Hens $\mathrm{N}$, et al. The impact of regular school closure on seasonal influenza epidemics: a data-driven spatial transmission model for Belgium. BMC infectious diseases. 2018;18(1):29.

6. Rundle AG, Park Y, Herbstman JB, Kinsey EW, Wang YC. COVID-19-Related School Closings and Risk of Weight Gain Among Children. Obesity (Silver Spring, Md). 2020;28(6):1008-9.

7. Kang E. Impact of Disasters on Community Medical Screening Examination and Vaccination Rates: The Case of the Sewol Ferry Disaster in Ansan, Korea. Disaster medicine and public health preparedness. 2020:1-6.

8. Rainey JJ, Sugerman D, Brennan M, Cadet JR, Ernsly $\mathrm{J}$, Lacapère $\mathrm{F}$, et al. Rapid monitoring in vaccination campaigns during emergencies: the post-earthquake campaign in Haiti. Bulletin of the World Health Organization. 2013;91(12):957-62.

9. Bianchini S, Argentiero A, Camilloni B, Silvestri E, Alunno A, Esposito S. Vaccination against Paediatric Respiratory Pathogens. Vaccines. 2019;7(4).

10. Hutchins SS, Jansen HA, Robertson SE, Evans P, Kim-Farley RJ. Studies of missed opportunities for immunization in developing and industrialized countries. Bulletin of the World Health Organization. 1993;71(5):549-60.

11. Gindler JS, Cutts FT, Barnett-Antinori ME, Zell ER, Swint EB, Hadler SC, et al. Successes and failures in vaccine delivery: evaluation of the immunization delivery system in Puerto Rico. Pediatrics. 1993;91(2):315-20.

12. Burton A, Monasch R, Lautenbach B, Gacic-Dobo M, Neill M, Karimov R, et al. WHO and UNICEF estimates of national infant immunization coverage: methods and processes. Bulletin of the World Health Organization. 2009;87(7):535-41.
13. Kiseleva I. New Points of Departure for More Global Influenza Vaccine Use. Vaccines. 2020;8(3).

14. Lernout $\mathrm{T}$, Theeten $\mathrm{H}$, Hens $\mathrm{N}$, Braeckman $\mathrm{T}$, Roelants M, Hoppenbrouwers K, et al. Timeliness of infant vaccination and factors related with delay in Flanders, Belgium. Vaccine. 2014;32(2):284-9.

15. Walton S, Cortina-Borja M, Dezateux C, Griffiths LJ, Tingay K, Akbari A, et al. Measuring the timeliness of childhood vaccinations: Using cohort data and routine health records to evaluate quality of immunisation services. Vaccine. 2017;35(51):7166-73.

16. Hasanain FH, Jan MM. Delays in primary vaccination of infants living in Western Saudi Arabia. Saudi medical journal. 2002;23(9):1087-9.

17. Banjari MA, Alamri AA, Algarni AY, Abualjadayel MH, Alshardi YS, Alahmadi TS. How often do children receive their vaccinations late, and why? Saudi medical journal. 2018;39(4):347-53.

18. Chan EYY, Man AYT, Lam HCY. Scientific evidence on natural disasters and health emergency and disaster risk management in Asian rural-based area. Br Med Bull. 2019;129(1):91105.

19. Bell S, Clarke R, Paterson P, Mounier-Jack S. Parents' and guardians' views and experiences of accessing routine childhood vaccinations during the coronavirus (COVID-19) pandemic: A mixed methods study in England. PloS one. 2020;15(12):e0244049-e.

20. Bechini A, Garamella G, Giammarco B, Zanella $\mathrm{B}$, Flori $\mathrm{V}$, Bonanni $\mathrm{P}$, et al. Paediatric activities and adherence to vaccinations during the COVID19 epidemic period in Tuscany, Italy: a survey of paediatricians. Journal of preventive medicine and hygiene. 2020;61(2):E125-e9.

21. Sokol RL, Grummon AH. COVID-19 and Parent Intention to Vaccinate Their Children Against Influenza. Pediatrics. 2020;146(6). 
Journal of Healthcare Sciences

22. Liberati A, Altman DG, Tetzlaff J, Mulrow C, Gøtzsche PC, Ioannidis JPA, et al. The PRISMA statement for reporting systematic reviews and meta-analyses of studies that evaluate healthcare interventions: explanation and elaboration. BMJ. 2009;339:b2700.

23. Newcastle- Ottawa: Quality assessment scale adapted for cross-sectional studies.

24. Alsuhaibani M, Alaqeel A. Impact of the COVID19 Pandemic on Routine Childhood Immunization in Saudi Arabia. Vaccines. 2020;8(4).

25. Alrabiaah AA, Alshaer AH, Estrella SMC, Inclan KAS, Aljammaz HA, Almoosa KM, et al. Effects of the Coronavirus disease 2019 pandemic on routine pediatric immunization coverage rates at the main University Hospital in Saudi Arabia. Saudi medical journal. 2020;41(11):1197-203.

26. Zainab A, ? H, Alhamoud, Alkhalaf A, Alabdullah $\mathrm{W}$, Alghafli J, et al. Impact of Coronavirus Disease 2019 (COVID-19) pandemic on routine pediatric vaccination in Eastern Region, Saudi Arabia. Journal of Medical Science. 2020:467281.

27. Santoli JM, Lindley MC, DeSilva MB, Kharbanda EO, Daley MF, Galloway L, et al. Effects of the COVID-19 Pandemic on Routine Pediatric Vaccine
Ordering and Administration - United States, 2020. MMWR Morbidity and mortality weekly report. 2020;69(19):591-3.

28. Chandir S, Siddiqi DA, Setayesh H, Khan AJ. Impact of COVID-19 lockdown on routine immunisation in Karachi, Pakistan. The Lancet Global health. 2020;8(9):e1118-e20.

29. McDonald HI, Tessier E, White JM, Woodruff M, Knowles C, Bates C, et al. Early impact of the coronavirus disease (COVID-19) pandemic and physical distancing measures on routine childhood vaccinations in England, January to April 2020. Euro surveillance : bulletin Europeen sur les maladies transmissibles $=$ European communicable disease bulletin. 2020;25(19).

30. Isaac MR, Chartier M, Brownell M, Chateau D, Nickel NC, Martens P, et al. Can opportunities be enhanced for vaccinating children in home visiting programs? A population-based cohort study. BMC public health. 2015;15:620.

31. Sartori AL, Minamisava R, Afonso ET, Policena GM, Pessoni GC, Bierrenbach AL, et al. Timeliness and risk factors associated with delay for pneumococcal conjugate 10-valent routine immunization in Brazilian children. Vaccine. 2017;35(7):1030-6. 